\title{
TEMPORAL LOBECTOMY FOR COMPLEX PARTIAL SEIZURES
}

The results of anterior temporal lobectomy performed for medically intractable, complex partial seizures, with onset before 16 years of age, in 42 consecutive patients are reported from various centers. All patients underwent surgery at the Children's Hospital, Boston, between 1972 and 1987, before implanted electrodes were routine. Total or near total seizure control was achieved in $85 \%$. ( $96 \%$ of 28 operated after the introduction of long-term EEG monitoring). Results were comparable to series using invasive monitoring. Post-operative follow-up was at least 2 years. The median age at operation was 17 years (range 3.9-27 years) in the seizure-free group compared to 20 years (range 12-34 years) in the group with persistent seizures after surgery. (Erba G et al. Temporal lobectomy for complex partial seizures that began in childhood. Surg Neurol Dec 1992; 38: 424-432). (Reprints: Ken R Winston MD, Box B467, Children's Health Center, 1950 Ogden St, Denver, CO 80218).

COMMENT. Patients may be selected successfully for temporal resection without the risk and expense of invasive presurgical depth electrodes and subdural monitoring. Neoplasm was the cause of seizures in $57 \%$, and surgery at an earlier age may have improved prognosis and seizure control. The outcome from anterior temporal resection in patients with localized lesions was particularly favorable. Positron emission tomography showing temporal hypometabolism correlated with good outcome following temporal lobectomy for uncontrolled seizures in a study of 53 patients at the National Institutes of Health (Theodore WH et al. Ann Neurol Dec 1992; 32: 789). PET identified the seizure focus and allowed limitation of invasive electrode placements for mapping.

\section{HEMIPLEGIC SYNDROMES}

\section{AUTOSOMAL DOMINANT ALTERNATING HEMIPLEGIA}

The familial occurrence and autosomal dominant inheritance of alternating hemiplegia of childhood is reported from Children's Hospital, and Massachusetts General Hospital, Harvard Medical School, Boston. Hemiplegic attacks without preceding seizure activity occurred in the proband, a 9-yearold, developmentally retarded boy, during the first year of life. Choreoathetosis and dystonic posturing were noted between attacks. Father, brother, paternal uncle, and paternal grandmother had histories of alternating hemiplegia. Stroke, neurodegenerative disease, and other causes were excluded. The karyotype showed a translocation, 46,XY,t $(3 ; 9)(\mathrm{p} 26 ; \mathrm{q} 34)$ in the patient and affected relatives. Flunarizine decreased attack frequency $>70 \%$. (Mikati MA et al. A syndrome of autosomal dominant alternating hemiplegia: Clinical presentation mimicking intractable epilepsy; chromosomal studies; and physiological investigations. Neurology Dec 1992; 42: 2251-2257). (Reprints: 
Dr Mohamad Mikati, Department of Neurology, Division of Neurophysiology, Hunnewell 2, Children's Hospital, Boston, MA 02115).

COMMENT. This is the first description of truly familial alternating hemiplegia, a syndrome of unknown etiology. The authors favor neurovascular or metabolic, rather than epileptic mechanisms.

Sakuragawa $\mathrm{N}$ reports 23 cases in an excellent review article from the National Institute of Neuroscience, Ogawa Higashi-cho, Kodaira-shi, Tokyo 187, Japan ( Brain Dev Sept 1992; 14: 283-8). The classification of alternating hemiplegia as a migraine variant is discussed.

\section{HEMIPLEGIA WITH SUPERIOR SAGITTAL SINUS THROMBOSIS}

A 2-year-old boy who developed a thrombosis of the superior sagittal sinus due to inherited protein $S$ deficiency is reported from the Hospital de Cruces, Vizcaya, Spain. While recovering from pneumonia, the patient had symptoms of an acute disseminated intravascular coagulation disorder associated with sinus thrombosis, left hemiparesis, focal seizures, and thrombosis of the left femoral vein. The paresis resolved within two months. (Prats JM et al. Superior sagittal sinus thrombosis in a child with protein $\mathrm{S}$ deficiency. Neurology Dec 1992; 4.2: 2303-5). (Reprints: Dr Jose Maria Prats, Neuropediatric Unit, Hospital de Cruces, 48903 Baracaldo, Vizcaya, Spain).

COMMENT. Homozygous protein S deficiency, an autosomal dominant trait with partial penetrance, usually presents with purpura fulminans in the newborn period. Heterozygous cases are responsible for recurrent peripheral thromboembolisms mainly in adults. Cerebral venous thrombosis is a rare complication of protein $S$ deficiency, but should be considered in the etiology of acute hemiparesis in children.

\section{RASMUSSEN'S SYNDROME AND UVEITIS}

Two children with Rasmussen's syndrome complicated by asymptomatic uveitis are reported from the Royal Children's Hospital, Melbourne, Australia, and Montreal Neurological Institute, Montreal, Canada. A 10-year-old girl developed somatosensorimotor seizures affected her right leg and left sided acute uveitis. Epilepsia partialis continua, with onset 9 months later, was associated with right hemiparesis and cortical sensory loss, and dysphasia. EEG showed epileptic discharges in the left central region. CT revealed atrophy of the left hemisphere. Left frontal corticectomy failed to control seizures. The cortex showed chronic encephalitis. The second patient, a 5-year-old girl, had complex partial status epilepticus which responded to IV gammaglobulin, left facial weakness, and right sided uveitis. Right anterior temporal lobectomy revealed leptomeningeal inflammation. Seizures became intractable, and a 